\title{
Effective Methods to Improve the Educational Process of Medicine in Bulgaria
}

\author{
Galya N. Georgieva-Tsaneva \\ Institute of Robotics \\ Bulgarian Academy of Sciences \\ Sofia, Bulgaria
}

\begin{abstract}
The introduction of modern technologies into the educational process of medical students is a challenge of the new era in education, which can increase the success of students and give them confidence in their capabilities. The paper considers the use of physiological clinical record databases as an effective means of gaining prior experience from students that will be of use to them in their professional work. The paper describes the entering of serious educational games into the learning process of students in Bulgaria. The serious games and the pedagogical methods applied therein are an innovative technological means of developing individual, social and cognitive qualities on which the individual's professional realization depends. The paper presents the results of a survey conducted at the universities of medical education in Bulgaria. Respondents' opinion of their desire to use serious games in their training and how games affect them has been studied and shown.
\end{abstract}

Keywords-Serious educational games; learning process; gaming training; pedagogical methods; innovative technological means; medical education

\section{INTRODUCTION}

Modern medical student education approaches and methods include information and communication technology as an innovative, effective, and next-generation student-centered tool.

One of the methods for improving the education of medical students is to create and use databases of real physiological data of patients, through which students can get acquainted with the real data of patients obtained through clinical research. The creation of logbooks containing data to track the development of the disease enables future physicians to monitor the results of the assigned treatment. The analysis of clinical data through appropriate mathematical technologies for the processing and analysis of physiological data is an effective tool for improving the education of medical students.

Another effective method of entering medical training is serious educational games. Today, technologies are complementary to traditional teaching methods [1] and are good practice for raising students' attention [2]. Over the years, serious games have become interactive software systems that can offer educational information and attractively generate specialized skills. Serious educational games in medicine can be an essential and valuable element of students' theoretical and practical training. In this way, serious games have the potential to integrate into the learning process and to help improve students' educational outcomes.
This paper considers serious educational games as a modern innovative tool for creating knowledge, skills, and habits among medical students by integrating medicine, computer technology and the attractive form of teaching methods of game situations. Entering confident medical training can make serious games an indispensable part of that training.

Over the last decades, Serious Educational Games (SEGs) are increasingly entering the education process in schools around the world [3], and recent years in Bulgaria. The aim of the Serious Educational Games is to support, supplement and upgrade traditional learning and the aim is different from ordinary fun games. Serious games enable their users to practice what they learn, test themselves, evaluate and increase their knowledge in an engaging, motivating and modern technological environment. SEGs use state-of-the-art visualization and simulation technologies [4] and they can be used both in the school environment and at home, at any time and everywhere, challenging learners to explore strange processes and phenomena, and putting them in a stimulating, competitive but a safe learning environment. SEGs enable the application of the principle of adaptability to the particular player and thus become maximally useful for each of their users, while the knowledge given in the form of a game enables the processing of high-difficulty learning content and the achievement of good absorption of a larger quantity of material; this method will contribute in the long run to improving students' abilities and for higher educational outcomes.

The report aims to show the main pedagogical characteristics of the SEGs and the impact of serious games on the learning outcomes.

The report presents the results of a study done among students in Bulgaria on the use of SEGs in the learning process, about the interest of the students in the inclusion of Serious Educational Games in their training and to study the impact of SEGs on the learning process in Bulgaria.

The importance of this research stems from the use of real physiological data to conduct mathematical medical analyzes and the achievement of educational goals in medical education (raising students' interest and creating an initial experience in working with medical data). The survey about serious games has specific objectives and is limited to the use of serious games in medical education in higher education. 
The rest of the paper is summarized as follows: Literature survey is shown in Section II. In Section III are presented modern methods for application in the educational process. Section IV presents the results of a mathematical analysis of Holter data and Section V presents the results of a study among medical students in Bulgaria. Conclusions are described in Section VI.

\section{RESEARCH BACKGROUND}

Today, the classical model of learning through passive perception is not efficient for the new generation of students [5], often even boring. Today's modern education must, therefore, comply with the requirements of the new innovative technological age.

Modern technologies today offer a variety of tools that can be implemented in the educational process, helping to increase its effectiveness. Internet technologies are a prerequisite for the creation and use of large volumes of physiological data that once created can be used at any time, from anywhere in the world. In the field of medicine, effective databases have been created that are used by the scientific research community and are a valuable resource for the development of research [6].

In the field of cardiology, there is a wide range of publicly available physiological databases. Most of the records in them are obtained through Holter monitoring and are sorted according to some classification features. The most popular and with the most physiological records database is PhysioBank, which contains 75 freely downloadable databases. The records are for patients with various cardiac disorders: heart failure, sudden cardiac death, sleep apnea, and more. The MIT-BIH databases (containing records of cardiac arrhythmias suitable for cardiac dynamics testing) [7] [8]; the AHA (American Heart Association) database (containing twochannel three-hour Holter records, parts of which are manually annotated); European ST-T Database (annotated, containing excerpts from ambulatory electrocardiographic records) [9]; ECG-ViEW II (containing digital parameters of the electrocardiogram) are also publicly available. Information from all these publicly available databases can be retrieved, analyzed with mathematical technology through software systems [10], and used as an additional training tool by medical students.

Other innovative educational tools today are serious educational games. Game-based education can be implemented in the following two ways: through the instructional model: students play serious games developed by a teacher or other developer and constructivist model: learners learn by designing and playing games created by themselves.

SEGs help the learning process by making and creating the author's things, engaging learners actively in the process of learning [11]. The use of serious educational games in student education is a challenge and is placed on the agenda for teacher and learner surveys [12]. The positive impact of games on the learning process has been explored by many authors. Boeker, Andel, Vach, \& Frankenschmidt [13] present the results of a study conducted among students divided into two groups: one group in the training included SEGs and the other one did not. The results show higher learning success in games including games. The authors Pettit, McCoy, Kinney, \& Schwartz in [14] conduct a study among students, which shows an increase in the efficiency of the training during inclusion in the training hours of the SEGs.

The main features of serious games were studied and presented in 2017 by the authors Bigdeli, \& Kaufman [12], adding the pedagogical aspect of the impact of games in the learning process:

- Single player or multiple player's participation;

- Conflicts creating;

- Clearly defined rules;

- The predetermined goal of the game;

- Artificial nature of games;

- The pedagogical nature of the serious game.

\section{ApPliCAtion OF InNOVAtive Methods IN THE LEARNING PROCESS}

\section{A. Benefits of Serious Games}

The training in all areas of knowledge can be effectively helped by the creation of innovative, serious learning games. The student training through serious education games has the potential, thanks to the following benefits it gives:

- Breaking the traditional concepts of learning related to a particular place of learning and certain hours during which it is happening, by offering free choice of place and learning time;

- Opportunities to customize the user interface of the serious educational game with the individual speed and individual learning characteristics of each particular user;

- Developing the ability to solve tasks assigned by the teacher in University independently;

- Opportunities for joint training of a group of users and development of teamwork skills.

Benefits of Incorporating Innovative Serious Games in the Higher Education Training Process:

- Providing computer-aided training;

- Creating an interactive virtual reality;

- Making timely feedback by offering different forms of encouragement to achieve progress and success that have a stimulating impact on learners;

- Creating opportunities for the learner to learn from his / her experience;

- Supporting the educational learning process by experimenting, researching, generating and verifying hypotheses;

- Raising the motivation for training through the racing character of the serious game; 
- Ability to raise the level of difficulty for the game, which assists in the acquisition of knowledge at a higher level; increasing time spent in SEGs, leading to higher education learning outcomes and raising the level of skills and competencies of learners;

- Serious educational games offer a comprehensive view of new information through a variety of tools: using graphical, acoustic and other signaling tools to enhance learning outcomes.

Serious educational games can be seen as interactive visual systems that combine the benefits of traditional learning and the attractiveness, dynamics, and impact of computer games. Serious learning games engage students of all ages in a fun, unobtrusive and non-standard way, integrating into a whole fun, learning, and skill-building experience.

In serious educational games, there are the following benefits to the educational process [15]:

- cognitive element: develop creativity and create skills to solve real problems;

- motivational element: create a sense of conviction in their abilities, develop perseverance in achieving their goals;

- emotional element: create a sense of conviction in their abilities, develop perseverance in achieving their goals;

- social element: contribute to the socialization of participants.

In this way, the benefits of serious educational games develop many useful social, cognitive and individual qualities in the students who use them. Fig. 1 shows the main types of qualities in these three groups that develop the using of serious games in the learning process. The figure shows how many useful qualities are developed through serious games; these are qualities that are valuable to medical students; for example, the qualities of motivation and the ability to achieve the goal, combined with the attainment of excellent medical skills, can lead to the successful end of the treatment of patients with risk diseases.

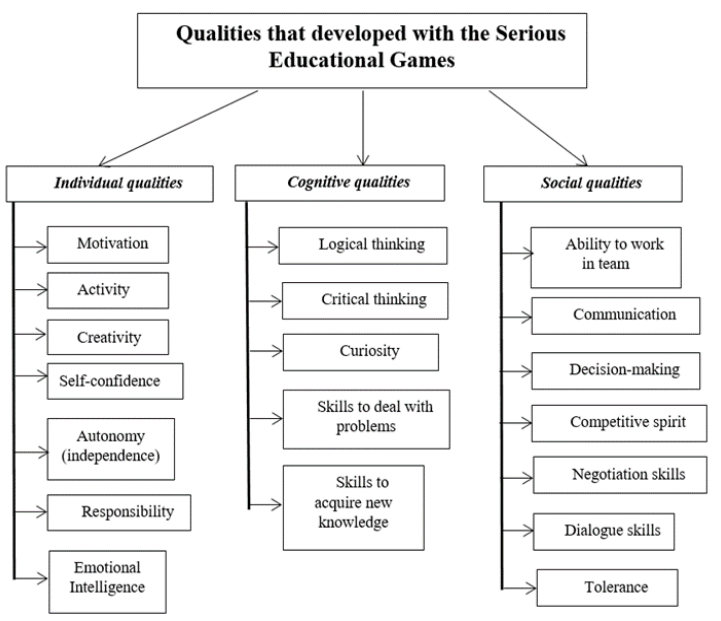

Fig. 1. The main Types of Qualities that Develop Serious Educational Games.
Serious games with their interactive way of conducting action are prerequisites for creating online socialization, new ways of interacting learners through online collaboration, an online based social environment, using verbal, computer-based ways of communicating and learning.

Fig. 2 shows the following major differences in characteristics between serious games (SG) and games that are played for fun (FG) (according to Isabela Granic et al [15]).

\section{B. The Pedagogical Capabilities of Serious Educational Games in the Learning Process}

According to Kolb [16], knowledge is best gained and strengthened by personal experience. SEGs are an excellent way to learn by building experiences, exploring and manipulating objects, building skills that are needed in teamwork and co-workers. An important feature of the good learning of teaching material in the learning process through serious educational games is the briefing: implementation of initial guidelines, briefly introduced by the lecturer, which puts right the foundations on which students can build their knowledge [17]. The following feature described by Rowe, Shores, Mott, \& Lester in [18] must also be considered: students with higher achievements have higher efficiency in solving new problems, they have a greater interest in collecting and organizing information. At the same time, however, students with higher achievements usually use traditional ways to solve the task, and lower-learning students prefer to use computer-based methods. In this way, SEGs can be used as a means to improve the learning educational results of students with a lower degree of learning.

\section{Methods to Achieve Educational Goals in Serious Games}

One of the leading methods for achieving educational goals through the use of serious games is the guiding principle of the teacher: to lay the foundations of new knowledge, guide, direct and correct, so that training through serious educational games can be truly effective, meaningful and not admitted the learner wasting time or moving in a different direction from a useful learning of the material.

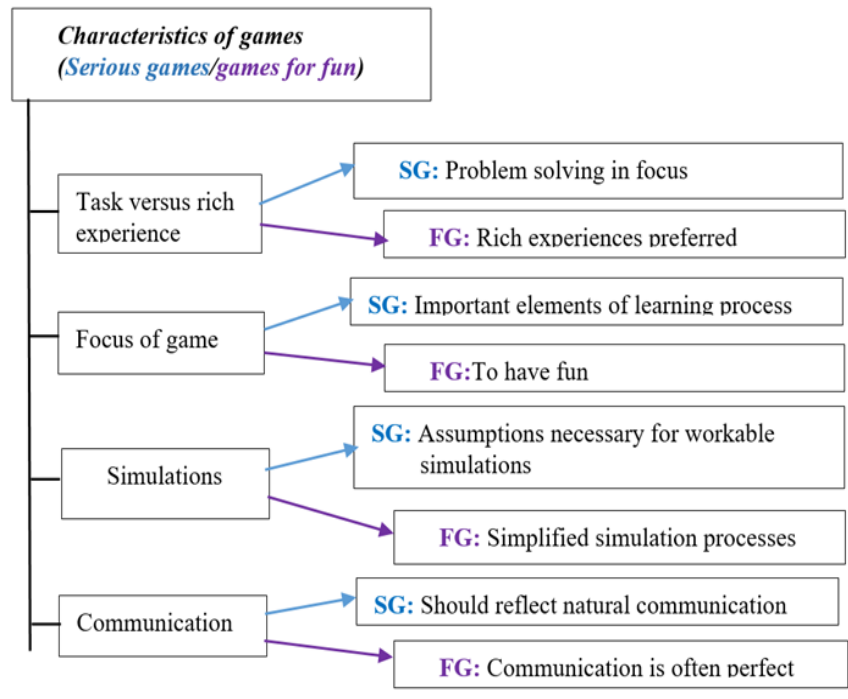

Fig. 2. Characteristics of Serious Games end Games for Fun. 
One of the important tasks of a game is to have the opportunity to adapt the game to the current knowledge, skills, and experience of the particular learner. In order to achieve the pedagogical goals of the training, the teacher needs to maintain a continuous dialogue with his / her pupils in order to keep track of their progress, the difficulties they encounter (to provide adequate help), analyze the information they receive about the student's achievements, to give advice, to support and correct the learning process.

In the scientific literature, eight component elements have been identified, identified and used to create a successful gameplay model (GameFlow): concentration, challenge, skills, control, clear goals, feedback, immersion, and social interaction [19]. For the optimal achievement of the educational goals of the games, it is good that all these principles are well established in them. Almost all games count on a clear goal and feedback. It is also necessary to strike a balance between the challenge of the game and the potential ability of the learner (according to his age, previous knowledge, and skills) to cope with it. Solving this task creates the learner's sense of satisfaction and builds confidence in his / her skills, which is one of the pedagogical tasks of teaching. An important task in creating serious educational games is to provide an opportunity to assess the player's progress and provide timely feedback.

\section{Current Contemporary World Trends and Innovative Technologies in the Field of Semantic Knowledge}

At the base of the Semantic Web (the concept is first used by the World Wide Web Consortium (W3C) Director) is the idea that innovative technologies can process data and interpret knowledge. The use of ontologies to present semantically based knowledge is a contemporary current global trend. Ontology is a means of creating a system of formally presented knowledge based on some accepted conceptualization - a description of a multitude of objects, notions, facts, knowledge and their interrelations. Ontology is a conceptual information model in a given area of knowledge in a formal way. Ontologies are very useful in creating search engines and information retrieval and are useful base in developing serious educational games in a given subject area of knowledge. One of the main goals of SEGs is to teach learners structured knowledge.

\section{E. Serious Games as a Method of Transferring Knowledge}

Serious educational games are increasingly becoming an alternative way of transferring knowledge in the area of knowledge they are targeting. SEGs are a method of conveying new, up-to-date knowledge that scientists, professionals, and explorers have reached, and by incorporating them into serious games, that knowledge can quickly and effectively reach the learners. Classical methods of transferring knowledge, such as specialized literature, learning through teaching, require a long time to master the educational material. In setting up SEGs it is useful to develop a design framework through which knowledge transfer is realized. It is a good idea to create a strategy for the dissemination of knowledge by designing algorithms to support decision-making.

\section{F. Exploring Consumer Opinion about Serious Educational Games}

The SEGs positive impact on education stems from an increase in the efficiency of the learning process, the possibility of additional self-learning of the learning material, consolidation of the acquired knowledge, support of unscheduled learning, effortless learning, increasing the interest in the studied subject and activation the participation of learners. At the same time, the entry of SEGs into Bulgarian education has been running for more than 10 years, and it is becoming increasingly popular among teachers who are beginning to assess their potential. Nowadays there are factors that support the use of games in educational schools and universities: provision of modern equipment in the renewed study rooms, increase of the number of SEGs set up in Bulgaria for the purpose of training students of different age groups and different subjects, provision of fast and quality Internet (especially in schools in larger settlements). For the comprehensive entry of the games into the learning process in Bulgaria, it is also necessary to conduct appropriate courses for teachers who want to modernize their teaching methods.

Serious educational games are suitable for assessing acquired knowledge, for extra-extra-curricular training, for home preparation, they can be an incentive for learning, they are appropriate for exercising the acquired knowledge, for achieving specific learning objectives, for building up the learning material.

From the respondents' answers, it is clear that they are willing to use serious educational games in the schooling process and for additional homework. It is also clear that innovative technologies in general and, in particular, serious educational games are not often used in the learning process. One of the main obstacles to the use of serious educational games in school is the lack of state-of-the-art technological equipment and the lack of appropriate SEGs that match the material studied, can be used in the limited time of the class, and the teachers have the appropriate technical competence to use of the Serious educational games. During the investigation, some of the teachers became interested, and they created serious games (textual to evaluate the material studied) and offered the pupils' games; games were received with interest.

\section{G. Use of Mathematical Technologies for Physiological Data Analysis in the Medical Education Process}

An effective technological method of analyzing physiological data is wavelet analysis. Used as an alternative to traditional Fourier analysis, Wavelet analysis is now widely used in various areas of real life and is a commonly used tool in scientific research. Wavelet analysis provides information on signal behavior simultaneously in the time and frequency domain and is suitable for use of non-stationary, dynamic signals such as cardiac signals.

The spectral analysis of cardiac data in the present study was performed using the wavelet-based method (continuous wavelet transform, wavelet basis of Morlet). Used interpolation of input data (resampled at $4 \mathrm{~Hz}$ ) through cubic spline wavelet. The results obtained are presented in digital and graphic form. 
The ratio (low frequencies / high frequencies) LF / HF obtained in the spectral analysis of the study series was investigated. this parameter is an indicator of sympathetic balance in the nervous regulation of the human body. According to the heart rate variability standard [20], values corresponding to a healthy organism are between 1.5 and 2.0.

\section{RESUlts OF A HOLTER DATA STUDY By MATHEMATICAL TOLLS}

A mathematical analysis of the cardiac data of a patient with atrial fibrillation was performed; the data were obtained through Holter monitoring conducted for 24 hours. The patient was admitted to a medical institution (Multiprofile Regional Hospital for Active Treatment MOBAL "Dr. Stefan Cherkezov", Cardiology ward, Veliko Tarnovo, Bulgaria). The Holter monitor device was installed (start time: 10.00 in the morning), after which the patient left the hospital, continuing throughout his 24-hour study to perform his normal daily activities.

The created software module (by the author) for analysis of cardiac data using Wavelet analysis was made and compiled in the MATLAB programming environment.

The cardiology series obtained after preprocessing input data (denoising, detection of peaks with maximum amplitude ( $R$ peak), etc.) obtaining the intervals between these peaks (RR intervals) is shown in Fig. 3.

Fig. 4 presents the distribution of frequencies depending on time (spectrogram of the investigated cardiac series, Atrial fibrillation) obtained using wavelet technology. The predominant blue areas in the low frequency (LF: $0.04-0.15 \mathrm{~Hz}$ ) and high frequency (HF: $0.15-0.4 \mathrm{~Hz}$ ) regions are an indicator of low signal power in the cardiology series studied, which is an indicator of serious health problems [21].

Fig. 5 presents the spectral components obtained in the analysis of the cardiac series tested (Very LF $(0.0-0.04 \mathrm{~Hz}$ ), LF and HF). Spectral components are calculated by applying three mathematical methods: the Burg method, the LombScargle method, and the Wavelet method. The calculated LF / HF ratio by these three methods is obtained outside the range of normal values for a healthy individual $(<1.5)$. The results obtained are an indicator of the presence of cardiac problems in the investigate subject.

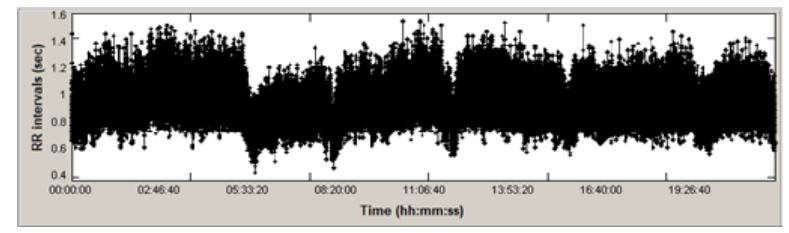

Fig. 3. The RR Intervals of the Studied Cardiology Sequence.

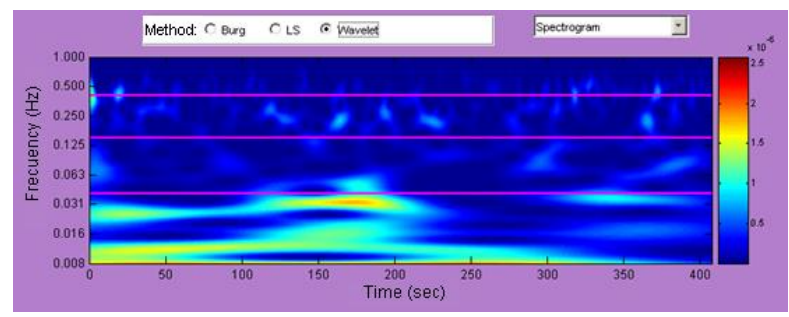

Fig. 4. Atrial Fibrillation Spectrogram.

\begin{tabular}{|c|c|c|c|c|c|}
\hline $\begin{array}{l}\text { Frecuency } \\
\text { band }\end{array}$ & $\begin{array}{r}\text { Peak } \\
(\mathrm{Hz})\end{array}$ & $\begin{array}{r}\text { Power } \\
\left(\mathrm{ms}^{2}\right)\end{array}$ & $\begin{array}{r}\text { Power } \\
(\%)\end{array}$ & $\begin{array}{c}\text { Power } \\
\text { (n.u.) }\end{array}$ & $\begin{array}{l}\text { LFHFF(ratio) } \\
\text { n.u.1.5-2.0 }\end{array}$ \\
\hline Burg & & & & & \\
\hline $\begin{array}{l}\text { MF } \\
\text { LF }\end{array}$ & $\begin{array}{l}0.04 \\
0.04\end{array}$ & $\begin{array}{l}25279 \\
528.7\end{array}$ & $\begin{array}{l}142 \\
290 \\
290\end{array}$ & 0.338 & 0.510 \\
\hline Lomb.scargle & & 10358 & & & \\
\hline Lf & $\begin{array}{l}0.04 \\
0.08\end{array}$ & $\begin{array}{l}160 \\
42.6 \\
4\end{array}$ & $\begin{array}{l}1113 \\
28.9\end{array}$ & 0.337 & 0.509 \\
\hline & & & & & \\
\hline$v_{F}$ & 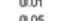 & 16128 & 28.5 & & $04 \%$ \\
\hline If & $\begin{array}{l}0.05 \\
0.23\end{array}$ & $\begin{array}{l}13282 \\
27214\end{array}$ & $\begin{array}{l}235 \\
481\end{array}$ & $\begin{array}{l}0.328 \\
0.572\end{array}$ & \\
\hline
\end{tabular}

Fig. 5. Wavelet Analysis Results.

\section{RESUlTS OF A SURVEY CONDUCTED AMONG BULGARIAN STUDENTS}

A study was conducted on the use of serious educational games by students in connection with their education in the country's higher universities. 162 students from the universities in Bulgaria, responded to the survey voluntarily. The study was conducted in April and May 2019, and participants were randomly selected. The survey aims to study the use of SEGs in the educational process in Bulgaria and to establish does it has to interest in the implementation of serious educational games in the classroom.

On the question "Do You play serious games related to your training" 42 students of all 162 responded with "Yes" (Fig. 6). This is a very small number of students and shows that the use of serious educational games in training in these universities is not well advocated.

On the question: "Do You think the serious games help to your training?" 134 of the respondents answered positively (Fig. 7), showing a high interest among students in the use of serious educational games for training and their positive attitude towards serious games.

\section{Do You play serious educational games related to your training?}

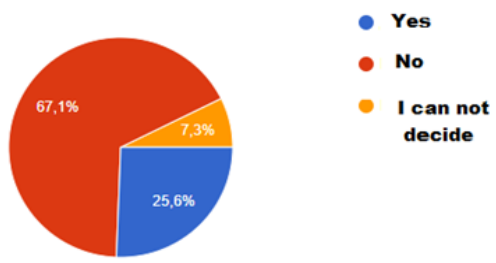

162 answers

Fig. 6. The use of Serious Educational Games in the Educational Process in Bulgaria.

Do You think the serious games help to the Your learning?
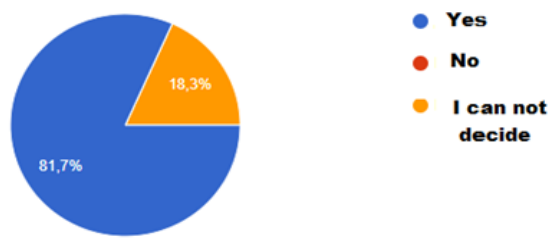

162 answers

Fig. 7. Studying Learners Attitudes Towards Serious Games. 
Of all 162 respondents, 142 students $(86.6 \%)$ believe that serious games will help raise learners' interest in the learning process (Fig. 8). Only 2 respondents have answered "No", and $12.2 \%$ said: "I cannot decide".

$126(0.78 \%)$ of all respondents believe that the inclusion of serious games in learning will increase their motivation to learn (Fig. 9). Six participants of the survey have answered "No", and $18.3 \%$ said: "I cannot decide".

The results of the conducted survey among students in Bulgaria show a positive attitude of students towards the inclusion of serious educational games in the learning process, willingness to use them and expect from the use of serious games to increase their interest in learning and motivation to achieve high educational results. At the same time, the study shows that today in Bulgarian universities the use of social security systems is not well advocated.

The conducted research on the means that students prefer to use in addition to traditional training tools in their medical education is summarized in Table I (Questions in questionnaire: "Do You want to use (Do use) these tools your university learning process"). The results show that students prefer to take advantage of modern technology in their training.

Table II presents the qualities that are developed through SEGs according to the respondents of the study (Question in the questionnaire: "Do serious games develop these qualities?"). The qualities that are developed through the use of SEGs are individual, collective and can enhance the educational outcomes of students.

\section{Do You think the serious games raise interest in the subject?}
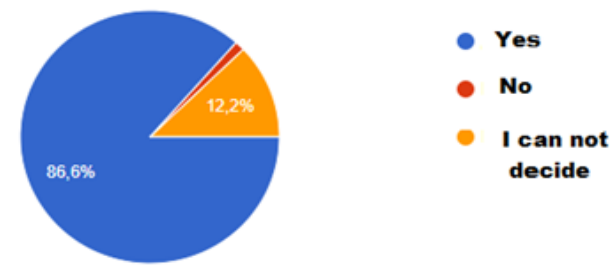

162 answers

Fig. 8. Answers to the Issue of Enhancing Motivation in Learning.

Do You think the serious games create better motivation for learning?

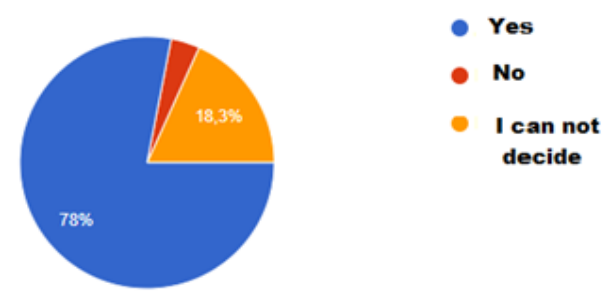

162 answers

Fig. 9. Answers to the Issue of Enhancing Motivation in Learning.

\section{A. Discussion on the use of SEGs in Training in Bulgaria}

Serious educational games today take advantage of new technologies and are becoming more challenging, intriguing and in line with the goals of the learning process. The set budget for a serious educational game has a great influence on the complexity, type of the game and the interesting and dynamic elements in the game. Today, gaming funds in the education sector (worldwide) are several times smaller than the funds spent on fun games creating. This leads to a lag in the technological and modernity of serious games in the education process.

Today, augmented and mixed reality technologies [22], effective graphical imaging tools (creating realistic controls for transparency, reflection, and refraction), content generation techniques are new challenges for improving serious games [23]. Open software platforms have been created to quickly create and easily personalize serious games that are beginning to be used by teachers in Bulgaria who want to stimulate their students' creativity and improve their skills and knowledge. Thus, the main problems, which will be decisive for the entry, development and use of serious games in higher education in Bulgaria and, respectively, in medical education at universities in the country, are the issue of financing serious games and the question of the desire of teachers to accept the challenge of game-based learning.

TABLE. I. MODERN TRAINING TOOLS

\begin{tabular}{|l|l|l|l|}
\hline Tools & $\begin{array}{l}\text { „I want to use (I } \\
\text { use) in the } \\
\text { learning process“6 }\end{array}$ & $\begin{array}{l}\text {,I do not want } \\
\text { to use in the } \\
\text { learning } \\
\text { process“6 }\end{array}$ & $\begin{array}{l}\text { "I cannot } \\
\text { decide" }\end{array}$ \\
\hline $\begin{array}{l}\text { Educational games } \\
\text { site }\end{array}$ & $74.69 \%$ & $2.47 \%$ & $22.84 \%$ \\
\hline $\begin{array}{l}\text { Interactive online } \\
\text { tests }\end{array}$ & $88.27 \%$ & $8.02 \%$ & $3.7 \%$ \\
\hline $\begin{array}{l}\text { Online video } \\
\text { training materials }\end{array}$ & $77.78 \%$ & $1.85 \%$ & $20.37 \%$ \\
\hline $\begin{array}{l}\text { Virtual and mixed } \\
\text { reality games }\end{array}$ & $51.23 \%$ & $20.99 \%$ & $27.78 \%$ \\
\hline $\begin{array}{l}\text { Databases with } \\
\text { real clinical data } \\
\text { and results }\end{array}$ & $85.8 \%$ & $7.4 \%$ & $6.79 \%$ \\
\hline $\begin{array}{l}\text { Software training } \\
\text { systems }\end{array}$ & $78.39 \%$ & $11.11 \%$ & $29.63 \%$ \\
\hline $\begin{array}{l}\text { Using graphics } \\
\text { tablets }\end{array}$ & $59.88 \%$ & $10.49 \%$ & \\
\hline
\end{tabular}

TABLE. II. DEVELOPED QUALITIES

\begin{tabular}{|l|l|l|l|}
\hline Qualities & ,Yes" & "No" & $\begin{array}{l}\text { "I cannot } \\
\text { decide" }\end{array}$ \\
\hline Communication skills & $74.69 \%$ & $17.9 \%$ & $7.4 \%$ \\
\hline Ability to work in a team & $69.75 \%$ & $16.05 \%$ & $14.2 \%$ \\
\hline A quick thought & $95.68 \%$ & $1.23 \%$ & $3.08 \%$ \\
\hline $\begin{array}{l}\text { Skills for coping with } \\
\text { difficulties }\end{array}$ & $88.89 \%$ & $4.94 \%$ & $6.17 \%$ \\
\hline $\begin{array}{l}\text { Orientation and adaptation in } \\
\text { extreme situations }\end{array}$ & $84.58 \%$ & $7.4 \%$ & $8.02 \%$ \\
\hline $\begin{array}{l}\text { Developing tactics and } \\
\text { strategies for achievement } \\
\text { of success }\end{array}$ & $79.63 \%$ & $9.88 \%$ & $10.49 \%$ \\
\hline
\end{tabular}




\section{CONCLUSION}

The paper presents two effective methods that can increase the motivation of medical students to learn and contribute to improving the quality of students' preparation: the use of mathematical technologies to analyze physiological data and the use of serious games in the educational process of medicine.

The paper examines the issues related to the use of Serious Educational Games, focusing on the pedagogical aspects of their use in the learning process.

Serious educational games aim to support traditional training by using the latest information and communication technologies developments and modern innovative methods.

The study conducted among students in Bulgaria shows a high interest in SEGs and their inclusion in the learning process. The majority of respondents believe that SEGs will contribute to improving their education, create student aspirations to build up the learning material, increase motivation for learning and professional development. As a result of the research, it can be concluded that students in Bulgaria will readily accept the use of serious educational games in their training and this will lead to the improvement of their knowledge, skills, and experience and will contribute to building them as excellent specialists in their area of professional interests.

\section{ACKNOWLEDGMENT}

This work was supported by NSF of Bulgaria under the Research project № DM 12/36/20.12.2017, "Investigation of Mathematical Techniques of Analysis of Physiological Data with Functionality for People with a Visual Deficit" and the Bulgarian Ministry of Education and Science under the National Research Programme "Young scientists and postdoctoral students" approved by DCM \# 577 / 17.08.2018.

\section{REFERENCES}

[1] A. Noorhidawati, S. Ghalebandi, R. Siti Hajar, "How Do Young Children Engage with Mobile Apps? Cognitive, Psychomotor, and Affective Perspective," Journal of Convergence Information Technology, Vol. 87, pp. 385-395, 2015.

[2] M. Prensky, Digital game-based learning, ACM Computers in Entertainment, 2003, Vol. 1, No 1, Book Two.

[3] J. Colbert, D. Chokshi, "Technology in Medical Education-Osler Meets Watson", Journal of General Internal Medicine, Vol. 29, No 12, pp. 1584-1585.

[4] P. Leger, P. Charland, H. Feldstein, J. Robert, G. Babin, D. Lyle, "Business Simulation Training in Information Technology Education: Guidelines for New Approaches in IT Training", Journal of Information Technology Education, Vol. 10, pp. 39-53, 2011.

[5] M. Larsen, "Advice for New and Student Lectures on Probability and Statistics", Journal of Statistics Education, Vol.14, No 1, pp. 1-13, 2006.

[6] G. Georgieva-Tsaneva, "Effective information methods for description and storage of data in health care", International Journal of Mechanical Engineering and Technology, Vol. 10, No 2, pp.708-715, 2019.
[7] G. B. Moody, R. G. Mark, "The impact of the MIT-BIH arrhythmia database", IEEE Engineering in Medicine and Biology Magazine, 2001, pp. 45-50.

[8] G. B. Moody, R. G. Mark, "The MIT-BIH arrhythmia database on CDROM and software for use with it", IEEE Computers in Cardiology, 1990, pp. 185-188.

[9] A. Taddei, A. Biagini, et al., The European ST - T database: Development, distribution and use, IEEE Computers in Cardiology, 1991, pp. 177-180.

[10] G. Georgieva-Tsaneva, "Wavelet based interval varying algorithm for optimal non-stationary signal denoising", Proceedings of the 20th International Conference on Computer Systems and Technologies, ACM International Conference Proceeding Series, New York, USA, pp.200206, 2019.

[11] Z.L. Márkus, G. Kaposi, M. Veres, Z. Weisz, G. Szántó, T. Szkaliczki, D. Paneva-Marinova, R. Pavlov, D. Luchev, M. Goynov, L. Pavlova, Interactive Game Development to Assist Cultural Heritage. Digital Presentation and Preservation of Cultural and Scientific Heritage. Vol. 8, Sofia, Bulgaria: Institute of Mathematics and Informatics - BAS, 2018, pp. 71-82, ISSN 1314-4006 (Print), eISSN 2535-0366 (Online).

[12] S. Bigdeli, D. Kaufman, "Digital games in medical education: Key terms, concepts, and definitions", Medical Journal of the Islamic Republic of Iran, Vol.31, No 1, pp. 300-306, 2017.

[13] M. Boeker, P. Andel, W. Vach, A. Frankenschmidt, "Game-based elearning is more effective than a conventional instructional method: A randomized controlled trial with third-year medical students", PloS one. Vol. 8; No 12: e82328, 2013. https://www.ncbi.nlm.nih.gov/pmc/ articles/PMC3857775/.

[14] K. Pettit, L. McCoy, M. Kinney, F. Schwartz, "Student perceptions of gamified audience response system interactions in large group lectures and via lecture capture technology". BMC Med educat. Vol.15, No 92, pp. 1-15, 2015.

[15] I. Granic, A. Lobel, R. Engels, "The benefits of playing video games". American Psychologist, Vol. 69(1), pp.66-78, 2014.

[16] D. Kolb, Experiential Learning. Prentice Hall, New York, 1984.

[17] A. Gloria, F. Bellotti, R. Berta, E. Lavagnino, "Serious Games for education and training", International Journal of Serious Games, Vol. 1, No. 1, pp. 100-105, 2014.

[18] P. Rowe, L. Shores, B. Mott, J. Lester, "Individual Differences in Gameplay and Learning: A Narrative-Centered Learning Perspective". In Proceedings of the Fifth International Conference on the Foundations of Digital Games, Monterey, 2010.

[19] P. Sweetser, P. Wyeth, "GameFlow: A Model for Evaluating Player Enjoyment in Games", ACM Computers in Entertainment, Vol. 3, No. 3, pp. 1-24, 2005).

[20] M. Malik, "Task Force of the European Society of Cardiology and the North American Society of Pacing and Electrophysiology. Heart rate variability: standards of measurement, physiological interpretation, and clinical use" Circulation, Vol. 93, 1996; pp. 1043-1065.

[21] C. Russoniello, Y.Zhirnov, V.Pougatchev, E.Gribkov, "HRV and Biological Age: Implications for Health and Gaming," Cyberpsych., Behav. Soc. Netw, Vol. 16, (4), 302-308,2013.

[22] M. Zyda, "From Visual Simulation to Virtual Reality to Games". IEEE Computer, Sept., Vol. 38 (9), pp. 25-32, 2005.

[23] G. N. Yannakakis, J. Togelius, "Experience-driven procedural content generation", IEEE, Transactions on Affective Computing, Vol. 2, No 3, pp.147-161, 2011. 